\title{
Effects of Coronary Artery Reperfusion on Myocardial Infarct Size Calculated from Creatine Kinase
}

\author{
Stephen F. Vatner, Hank Baig, W. Thomas Manders, and Peter R. Maroko, \\ Departments of Medicine, Harvard Medical School and Peter Bent Brigham \\ Hospital, the Department of Cardiology, Childrens' Hospital Medical Center, \\ Boston, Massachusetts 02115, and the New England Regional Primate Research \\ Center, Southboro, Massachusetts 01772
}

A B S T RAC T The effects of coronary artery reperfusion at 1 and $3 \mathrm{~h}$ after occlusion on infarct size (IS) in the conscious dog were compared with a second group of dogs that were not reperfused ( $24 \mathrm{~h}$ occlusion). Infarct size was calculated from creatine kinase (CK) appearing in blood samples ( $\mathrm{IS}_{\mathrm{s}}$ ) and myocardial CK depletion $\left(\mathrm{IS}_{\mathrm{m}}\right)$, and determined from gross and histological inspection of the pathological tissue $\left(\mathrm{IS}_{\mathrm{p}}\right)$. Under both conditions, IS $_{m}$ correlated well with $\mathrm{IS}_{\mathrm{p}}$. In dogs with 24-h coronary occlusions, IS $_{\mathrm{s}}$ correlated well with $\mathrm{IS}_{\mathrm{m}}\left(\mathrm{IS}_{\mathrm{s}}=14.26+1.18 \times \mathrm{IS}_{\mathrm{m}}, r=0.92\right)$. In reperfused dogs, the relationship remained linear but was altered $\left(\mathrm{IS}_{\mathrm{s}}=15.33+2.07 \times \mathrm{IS}_{\mathrm{m}}, r=0.89\right)$. The slope was significantly greater, $P<0.05$, than that observed for dogs that were not reperfused, suggesting that more CK appeared in serum per gram of infarct. Similarly, significantly different relationships were observed in the reperfused and nonreperfused dogs, when $\mathrm{IS}_{\mathrm{s}}$ was compared with $\mathrm{IS}_{\mathrm{p}}$. Moreover, the configuration of the serial blood CK curve was changed significantly by reperfusion. In dogs with a 24 -h occlusion, CK rose gradually to a peak at $11.4 \pm 0.5 \mathrm{~h}$. In dogs reperfused at $3 \mathrm{~h}, \mathrm{CK}$ rose sharply at $3 \mathrm{~h}$ and reached a peak at $6.8 \pm 0.5 \mathrm{~h}$, significantly earlier $(P<0.01)$ than occurred in dogs reperfused at $1 \mathrm{~h}$, i.e., when the peak occurred at $4.2 \pm 0.4 \mathrm{~h}$. The rapid appearance of $\mathrm{CK}$ in blood after reperfusion at 1 and $3 \mathrm{~h}$ suggested a washout phenomena. Thus, reperfusion alters the shape of the serial blood CK curve and results in a different linear relationship between calculated and measured infarct size, resulting in greater recovery of CK in blood per unit of infarcted myocardium.

Dr. Vatner is an Established Investigator for the American Heart Association.

Received for publication 11 August 1977 and in revised form 7 November 1977.

\section{INTRODUCTION}

The appearance of elevated blood levels of enzymes reflecting myocardial necrosis has become an important adjunct to the diagnosis of acute myocardial infarction (1-4). Moreover, a relationship between clinical prognosis and blood levels of enzymes after myocardial infarction has been shown by Chapman (5). More recently, Kjekshus and Sobel observed that a quantitative relationship existed between the size of experimental myocardial infarction and the depletion of creatine kinase $(\mathrm{CK})^{1}$ in the myocardium (6). Shell et al. (7) extended these observations and demonstrated that the size of experimental myocardial infarction as determined by myocardial CK depletion was linearly related to the amount of CK appearing in the blood over a 24 -h period. Since coronary artery reperfusion using the aorta-coronary bypass procedure is now important therapeutically, and since CK appearance in blood is used to measure myocardial necrosis, a clear understanding of the effects of reperfusion on blood and myocardial enzyme determinations is needed.

Prior studies examining the effects of reperfusion on the calculation of infarct size from the appearance of CK in blood have been conflicting $(8,9)$. Bresnahan et al. (8) felt that coronary artery reperfusion did not interfere with the calculation of infarct size, whereas Jarmakani et al. (9) felt that infarct size could not be calculated accurately from CK in blood either in the presence or absence of reperfusion. Accordingly, the goals of this study were to evaluate: $(a)$ the relationship between CK appearance in blood and myocardial infarct size as determined by myocardial CK depletion

${ }^{1}$ Abbreviations used in this paper: CK, creatine kinase; ISm, infarct size determined by myocardial CK depletion; ISp, infarct size determined by pathology; ISs, infarct size determined by CK appearance in blood. 
after a 24-h coronary occlusion; (b) this relationship in a separate series of dogs, in which reperfusion intervened; $(c)$ the relationship between myocardial infarct size determined by gross pathology (and confirmed by histology) and by myocardial CK depletion; and $(d)$ the extent to which occlusion of the left circumflex coronary artery produces a homogeneous area of infarction (10). Experiments were conducted in conscious dogs to avoid the effects of anesthesia on enzyme kinetics (7) and also because these animals remain hemodynamically stable after coronary occlusion (11).

\section{METHODS}

36 mongrel dogs (19-35) $\mathrm{kg})^{2}$ underwent a left thoracotomy using $30 \mathrm{mg} / \mathrm{kg} \mathrm{Na}$ pentobarbital anesthesia for implantation of a Doppler ultrasonic flow transducer and an hydraulic occluding cuff on either the left anterior descending (7 dogs) or circumflex coronary artery (29 dogs) and heparin-filled Tygon catheters (Norton Co., Tallmadge, Ohio) in the left atrium and aorta.

Experiments were conducted 3-6 wk after recovery from operation. After at least two control samples of blood were collected, the occluding cuff was inflated for $24 \mathrm{~h}$ in 19 dogs. Reperfusion was carried out $\mathrm{l} \mathrm{h}$ after occlusion in nine dogs and $3 \mathrm{~h}$ after occlusion in eight dogs. Total occlusion and reperfusion were confirmed using the Doppler ultrasonic flowmeter (12). This entailed continuous monitoring of the dogs for $24 \mathrm{~h}$ after occlusion. If partial release occurred in the 24-h occlusion group, this problem was rectified immediately. Serial samples of blood $(5 \mathrm{ml})$ were withdrawn from the dogs over a 24 -h period. The samples were taken hourly for the first $8 \mathrm{~h}$, then every $2 \mathrm{~h}$ for the next $8 \mathrm{~h}$, and every $4 \mathrm{~h}$ for the final $8 \mathrm{~h}$ and collected in tubes with ethylene glycol-bis ( $\beta$-aminoethyl ether) $N, N, N^{\prime}, N^{\prime}$-tetraacetate and centrifuged. The plasma was decanted and frozen immediately at $-70^{\circ} \mathrm{C}$.

After $24 \mathrm{~h}$ all dogs were anesthetized with $\mathrm{Na}$ pentobarbital and sacrificed. At the time of sacrifice, the heart was rapidly excised and washed repeatedly in iced saline. The atria, pulmonary artery, aorta, valvular apparatus, and the pericardial fat were excised and discarded. The free wall of the right ventricle was dissected, weighed, and immersed in the homogenizing medium for CK, i.e., $25 \mathrm{ml} / \mathrm{g}$ of myocardium in $0.25 \mathrm{M}$ sucrose, $0.001 \mathrm{M}$ neutralized sodium EDTA and $1 \mathrm{mM}$ mercaptoethanol. When the infarction extended to the right ventricle $(n=3)$, it was dissected and weighed separately. The left ventricular cavity was exposed longitudinally on the anterior surface when the circumflex was occluded, and on the diaphragmatic surface when the anterior descending coronary artery was occluded, in order to inspect the infarct, paying special attention to the presence of hemorrhage. Infarcted myocardium was dissected carefully from the remaining normal myocardium and weighed to determine infarct size by gross inspection. Identification of infarcted myocardium $24 \mathrm{~h}$ after occlusion was possible, since the infarcted area is clearly much paler, acquiring a white-yellowish color and at times is hemorrhagic. This procedure was verified by examining histologic sections with light microscopy.

In addition to separating and weighing the infarcted and the normal left ventricular myocardium, biopsies for CK were taken from the normal myocardium and the center of infarc-

\footnotetext{
${ }^{2}$ One dog weighed $62.5 \mathrm{~kg}$.
}

tion. The ventricular myocardium was minced with scissors and homogenized with the above described solution in a Waring blender (Waring Products Div., Dynamics Corp. of America, New Hartford, Conn.) (half speed, two 15-sec bursts). It was then centrifuged at $10,000 \mathrm{rpm}$ for $10 \mathrm{~min}$ at $0^{\circ} \mathrm{C}$ and the supernatant fraction removed and centrifuged at 16,000 $\mathrm{rpm}$ for $10 \mathrm{~min}$. The biopsies were homogenized in a VirTis 45 homogenizer (The VirTis Co., Gardiner, N. Y.) instead of the Waring blender (Waring Products Div.).

In all dogs infarct size (IS) was determined by gross pathological inspection $\left(\mathrm{IS}_{\mathrm{p}}\right.$ ) and compared with calculated infarct size from CK appearance in the blood samples (IS s $_{\mathrm{s}}$. Infarct size was also determined by myocardial CK depletion $\left(\mathbf{I S}_{\mathrm{m}}\right)$ in 11 dogs with 24-h occlusions and 14 dogs with reperfusion. $\mathrm{CK}$ was assayed using $\mathrm{CK}$ n-l reagent (Worthington Biochemical Corp., Freehold, N. J.). Protein contents of homogenates and of tissue fractions were determined by the biuret procedure (13). CK in plasma and tissue fractions was assayed spectrophotometrically as described by Rosalki (14). Results were expressed as International Units per milliliter, International Units per milligram protein, or International Units per milliliter per gram myocardium.

The techniques and formulas described by Shell et al. (7) were used to calculate IS $_{m}$ (Appendix I). The amount of CK depleted by the myocardium was calculated as the difference between CK concentration in normal myocardium and CK concentration measured in the homogenized entire left ventricle times left ventricular mass. The difference in CK concentration between normal areas and the center of the infarct was $74.6 \%$ of normal CK concentration. The techniques and formulas described by Shell et al. (7) were used to calculate IS $_{s}$ (Appendix II). To determine if the calculation of IS $_{s}$ would be altered by extrapolating the blood CK curve beyond $24 \mathrm{~h}$, an exponential function was fitted to the existing data points and extended to the time when $C K$ values would have returned to control levels, and the appropriate analyses were repeated.

All dogs were included in the comparison of the relationships among $\mathrm{IS}_{\mathrm{m}}, \mathrm{IS}_{\mathrm{s}}$ and $\mathrm{IS}_{\mathrm{p}}$. However, dogs exhibiting small infarcts were excluded from determinations where the inclusion of small infarcts or as in some cases, no infarction, would be misleading. For instance, in the determination of the ratio of average CK appearing in blood over $24 \mathrm{~h}$ to $\mathrm{IS}_{\mathrm{p}}$, and also of the amount of myocardial CK depleted per gram of infarct determined by pathology, it would be misleading to include small infarcts, i.e., $<10 \mathrm{~g}$ and in some cases, no infarction. The rationale for this becomes apparent when considering calculations of quotients with the denominator zero. Another important example where small infarcts were excluded was in the determination of the frequency of hemorrhagic infarction.

Linear regression analysis was used to examine relationships among infarct size measurements. The slopes were compared by calculating residual variances and using the $t$ distribution to test for significant differences (15). Infarct size relationships for both groups of reperfused animals were not significantly different and will be pooled. However, significant differences were observed in the shape of their respective serum CK curves and will be discussed.

\section{RESULTS}

\section{Effects of reperfusion on gross appearance of infarct}

Whereas the average size of infarct determined by gross pathology was similar in the 24 -h occlusion group 
$(23.2 \pm 4.6 \mathrm{~g})($ mean $\pm \mathrm{SEM})$ and the 1- and 3-h occlusion group (24.1 $\pm 5.2 \mathrm{~g}$ ), both groups showed marked variability in infarct size. For instance, left circumflex occlusion in the conscious dog, either in the presence or absence of reperfusion, resulted in infarcts ranging from 0 to $51.5 \mathrm{~g}$. There was, however, a significant difference in the appearance of the infarct because $23 \%$ of dogs with $24 \mathrm{~h}$ occlusion were grossly hemorrhagic when compared with $83 \%$ of the reperfused group $\left(\chi^{2}=6.82, P<0.01\right)$. Dogs with infarcts $<2 \mathrm{~g}$ were not included in this particular analysis, since the determination of the presence or absence of hemorrhagic infarction is meaningless, when infarction, per se, is minimal or nonexistent.

\section{Effects of reperfusion on serial blood CK curve}

After reperfusion there was a rapid appearance of $\mathrm{CK}$ in blood. In deriving the mean time to peak CK in blood for each of the three groups, small infarcts were excluded, since their depressed curves (or absence of a curve in the case of no infarct) would tend to obscure the prominent differences in shape in the presence of gross infarction caused by reperfusion. Both reperfusion at $1 \mathrm{~h}$ and $3 \mathrm{~h}$ resulted in alterations of the configuration of the blood CK curves from those obtained from dogs with 24-h occlusions (Fig. 1).

$24 \mathrm{~h}$ occlusion. CK in blood rose gradually from control reaching a peak level at $11.4 \pm 0.5 \mathrm{~h}$ (Figs. 1, 2).

$3 \mathrm{~h}$ occlusion. In contrast to the response with permanent occlusion, CK in blood rose more rapidly. CK sharply rose after reperfusion at $3 \mathrm{~h}$ and reached a peak at $6.8 \pm 0.5 \mathrm{~h}$, which was significantly earlier $(P<0.01)$ than occurred during 24 -h occlusions (Figs. $1,2)$.

1 h occlusion. CK in blood rose even more rapidly.

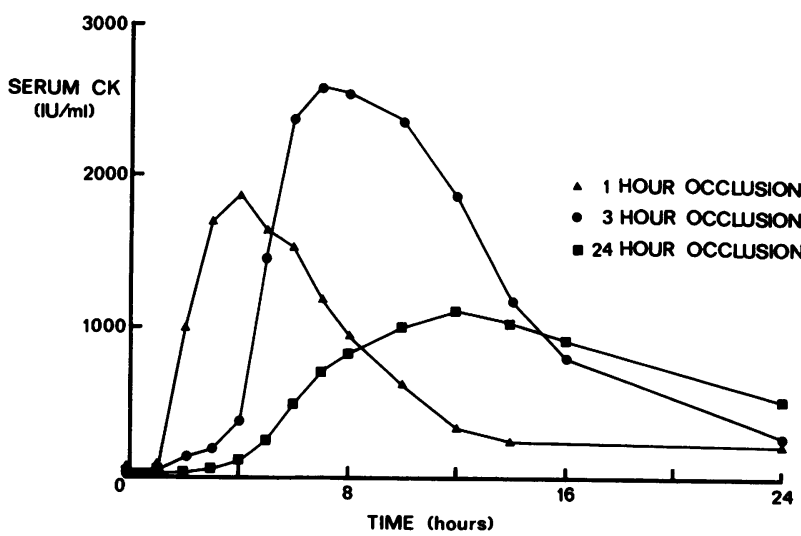

Figure 1 The different characteristic shapes of the serial blood CK curves for the three groups are shown by examples obtained from a dog with $24 \mathrm{~h}$ occlusion, a dog reperfused at $3 \mathrm{~h}$, and a dog reperfused at $1 \mathrm{~h}$. The rapid rise in CK in blood is evident after reperfusion.

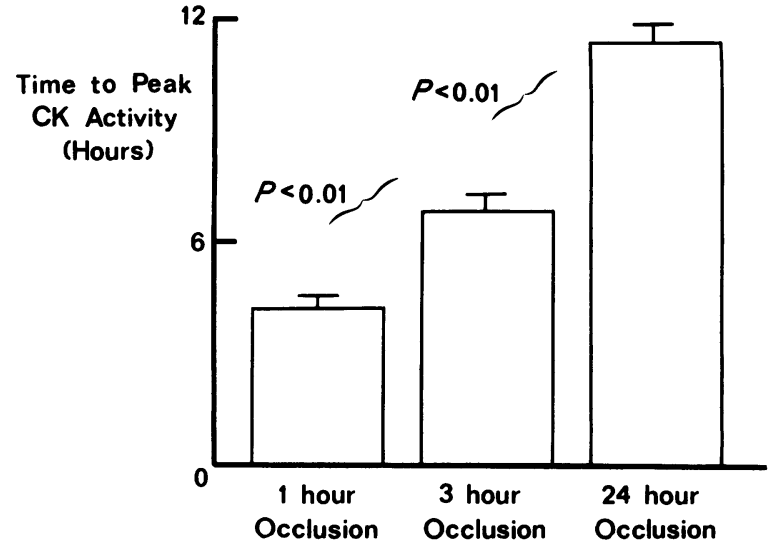

FIGURE 2 The average time to peak blood CK activity is compared for dogs reperfused at either 1 or $3 \mathrm{~h}$ and dogs with permanent occlusion. The time to peak blood CK activity was significantly different in the three groups $(P<0.01)$.

CK sharply rose after reperfusion at $1 \mathrm{~h}$, and reached a peak at $4.2 \pm 0.4 \mathrm{~h}$, significantly earlier $(P<0.02)$ than occurred in dogs reperfused at $3 \mathrm{~h}$ (Figs. 1, 2).

\section{Relationship between $I S_{s}$ and $I S_{m}$.}

24 h occlusion. A linear relationship was observed, $\mathrm{IS}_{\mathrm{s}}=14.26+1.18 \times \mathrm{IS}_{\mathrm{m}}, r=0.92$ (Fig. 3).

Reperfusion. While the relationship remained linear, it was altered: $\mathrm{IS}_{\mathrm{s}}=15.33+2.07 \times \mathrm{IS}_{\mathrm{m}}, r=0.89$ (Fig. 3). The slope was significantly greater, $P<0.05$, than observed for dogs that were not reperfused, suggesting that more CK appeared in blood per gram of infarct. This is supported by the observation that the average amount of CK appearing in blood over $24 \mathrm{~h}$ per gram of infarct determined by pathology, $764 \pm 117$ $\mathrm{IU} / \mathrm{ml}$ per $\mathrm{g} \times$ body $\mathrm{wt}$, was significantly greater, $P<0.02$, than in dogs with 24 -h occlusions, e.g. $408 \pm 29.5$ $\mathrm{IU} / \mathrm{ml}$ per $\mathrm{g} \times$ body wt.

When individual blood CK curves were extrapolated beyond $24 \mathrm{~h}$ to the time when CK had returned to control, these relationships became: IS $_{\mathrm{s}}=14.80+2.24$ $\times \mathrm{IS}_{\mathrm{m}}, r=0.92$ for the reperfused group; and $\mathrm{IS}_{\mathrm{s}}$ $=14.11+1.27 \times \mathrm{IS}_{\mathrm{m}}, r=0.95$ for the 24 -h occlusion group. Again, these slopes were significantly different, $P<0.02$, although only slightly altered from the values obtained from the respective nonextrapolated curves.

\section{Relationship between $I S_{p}$ and $I S_{m}$}

24 h occlusion. A linear relationship was observed, $\mathrm{IS}_{\mathrm{p}}=12.64+0.69 \times \mathrm{IS}_{\mathrm{m}}, r=0.87$ (Fig. 4). The amount of myocardial CK depleted per gram of infarct determined by gross inspection was $26.8 \pm 2.61 \mathrm{IU} / \mathrm{mg}$ of protein per $\mathrm{g}$ infarct.

Reperfusion. A similar relationship was observed, $\mathrm{IS}_{\mathrm{p}}=5.76+0.94 \times \mathrm{IS}_{\mathrm{m}}, \quad r=0.94$. The amount of 

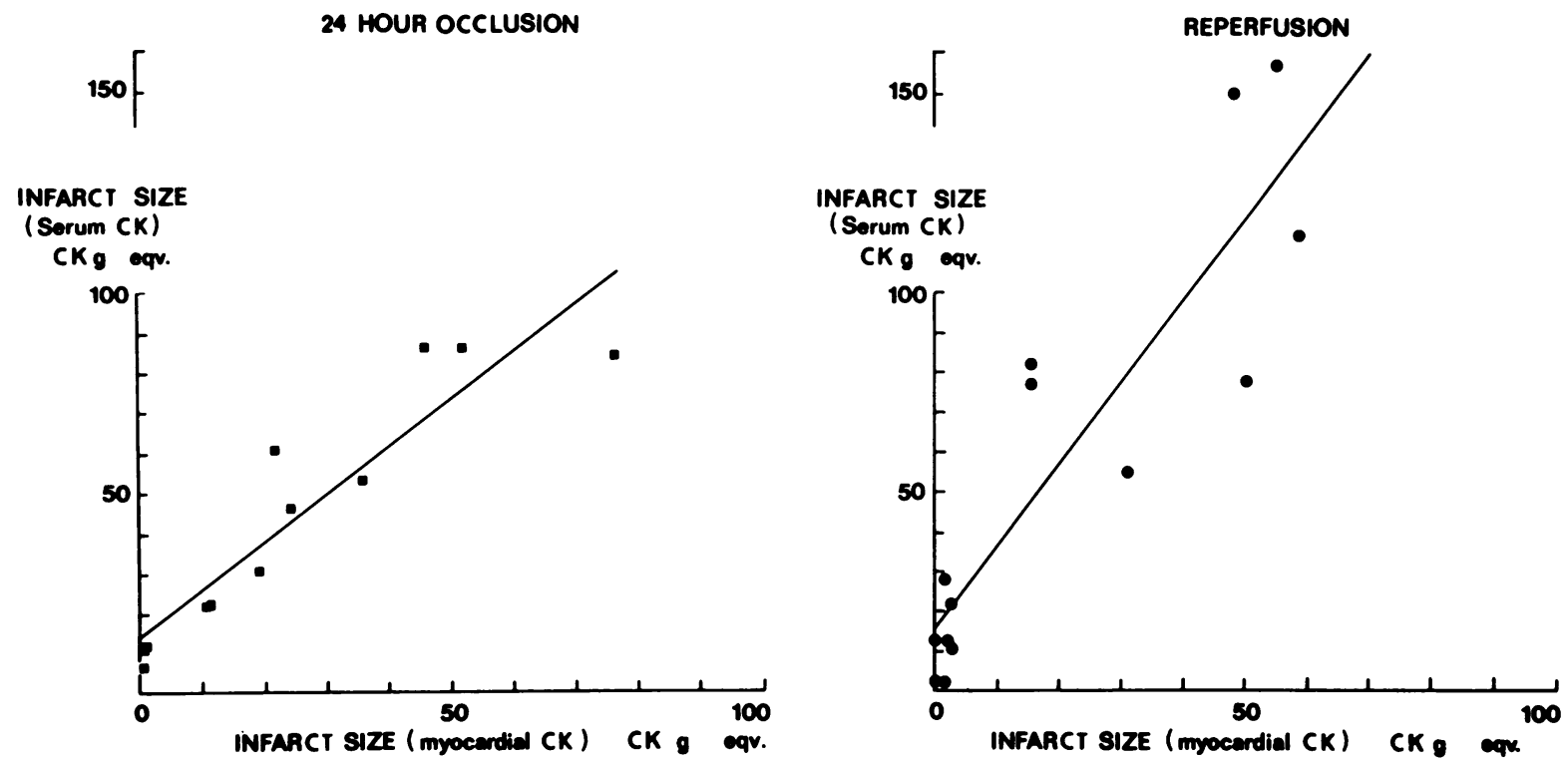

FIGURE 3 Infarct size calculated from appearance of CK in blood is plotted against infarct size calculated from myocardial CK depletion for 11 dogs with $24 \mathrm{~h}$ occlusion (left) and 14 dogs reperfused at 1 or $3 \mathrm{~h}$ (right). The slope of the regression line was significantly steeper $(P<0.05)$ in the reperfused group. The standard error of the estimate in the 24-h occlusion group was 12.81 , and in the reperfusion group was 25.13 .

myocardial CK depleted per gram of infarct determined by gross inspection was $23.6 \pm 4.71 \mathrm{IU} / \mathrm{mg}$ of protein per $\mathrm{g}$ infarct, which was not significantly different from that of the 24-h group.

\section{HOUR OCCLUSION}

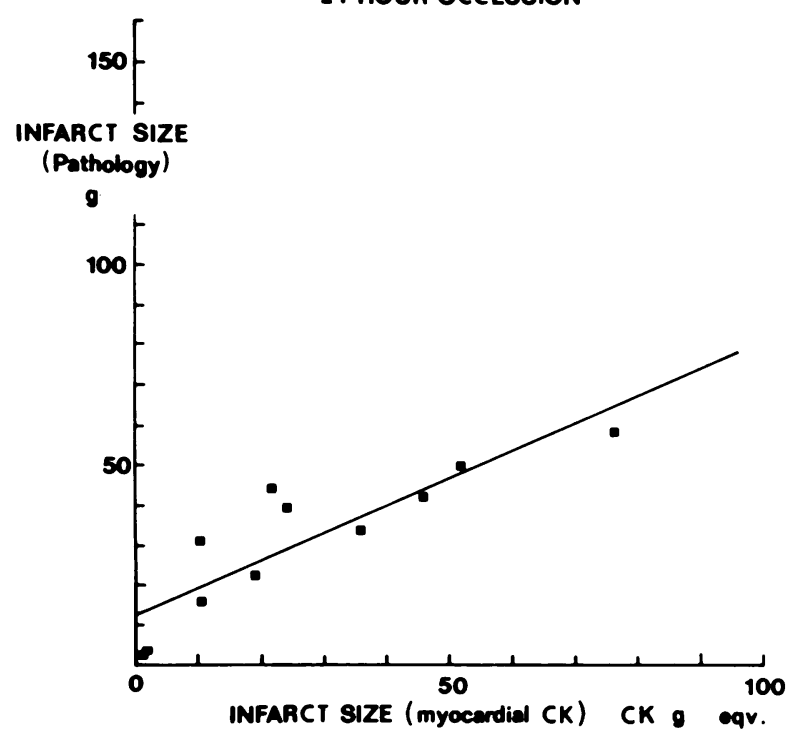

Relationship between $I S_{s}$ and $I S_{p}$

$24 \mathrm{~h}$ occlusion. A linear relationship was observed, $\mathrm{IS}_{\mathrm{s}}=2.50+1.38 \times \mathrm{IS}_{\mathrm{p}}, r=0.94$ (Fig. 5), which was

FIGURE 4 Infarct size determined by pathology is plotted against infarct size calculated by myocardial CK depletion for 11 dogs with 24-h occlusions (left) and 14 dogs reperfused (right). There are two overlapping data points near the origin in the reperfused group. The slopes of the regression lines were not significantly different. The standard error of the estimate was 9.45 for the permanent occlusion group, and 8.28 for the reperfused group. 
similar to that observed when infarct size was measured by myocardial CK depletion.

Reperfusion. This relationship was also linear, $\mathrm{IS}_{\mathrm{s}}=6.52+2.12 \times \mathrm{IS}_{\mathrm{p}}, r=0.90$, and also similar to that observed when infarct size was measured by myocardial CK depletion, but significantly different from that observed in dogs with 24-h occlusions, $P<0.02$ (Fig. 5).

\section{DISCUSSION}

Kjekshus and Sobel demonstrated that gross infarct size after a permanent $(24 \mathrm{~h})$ coronary occlusion correlated well with measurement of the CK depletion in the injured myocardium (6). Shell et al. (7) then demonstrated that the correlation between infarct size measured by myocardial CK depletion and calculated from CK in blood was excellent after $24 \mathrm{~h}$ occlusion in conscious dogs. However, no previous study has compared infarct size using a combination of all three techniques, e.g. (a) calculated from CK appearance in blood; (b) calculated from myocardial CK depletion; and $(c)$ pathological and histological analysis. In the present study, a good correlation was found between infarct size calculated from blood CK curves and calculated from myocardial CK depletion in dogs with $24 \mathrm{~h}$ coronary occlusion, although the blood CK technique tended to overestimate infarct size. This is consistent with the study of Shell et al. (7), Bleifeld et al. (16), and Norris et al. (17), but inconsistent with that of Roe et al. (18), where the correlation was not good. An important component of the present investigation, which was not included by Roe et al. (18), was the implantation of a flow probe on the occluded vessel to continuously confirm occlusion over the 24-h period in the present study. Without the continuous measurement of blood flow and an observer present to rectify any partial release, some of the animals in the present study would have undergone partial reperfusion at some time between 12 and $24 \mathrm{~h}$ after occlusion. If this had occurred, the relationship between calculated and measured infarct size in the 24-h occlusion group would not have been as good, since reperfusion alters this relationship.

One could argue that measurement of infarct size by pathological techniques would be subjective and prone to large error. If the present technique used for measurement of infarct size pathologically with histologic confirmation were accurate, then the correlation between the data using this technique and the independent one of Kjekshus and Sobel (6) which utilized measurement of myocardial CK depletion, should have been good. In fact, this was observed (Fig. 4). The linear relationships between infarct size measured pathologically and calculated from myocardial CK depletion, and also that between infarct size measured pathologically and calculated from blood CK curves, were found to be good for experimental myocardial infarction in conscious dogs with occlusions of $24 \mathrm{~h}$ duration, having correlation coefficients of

24 HOUR OCCLUSION
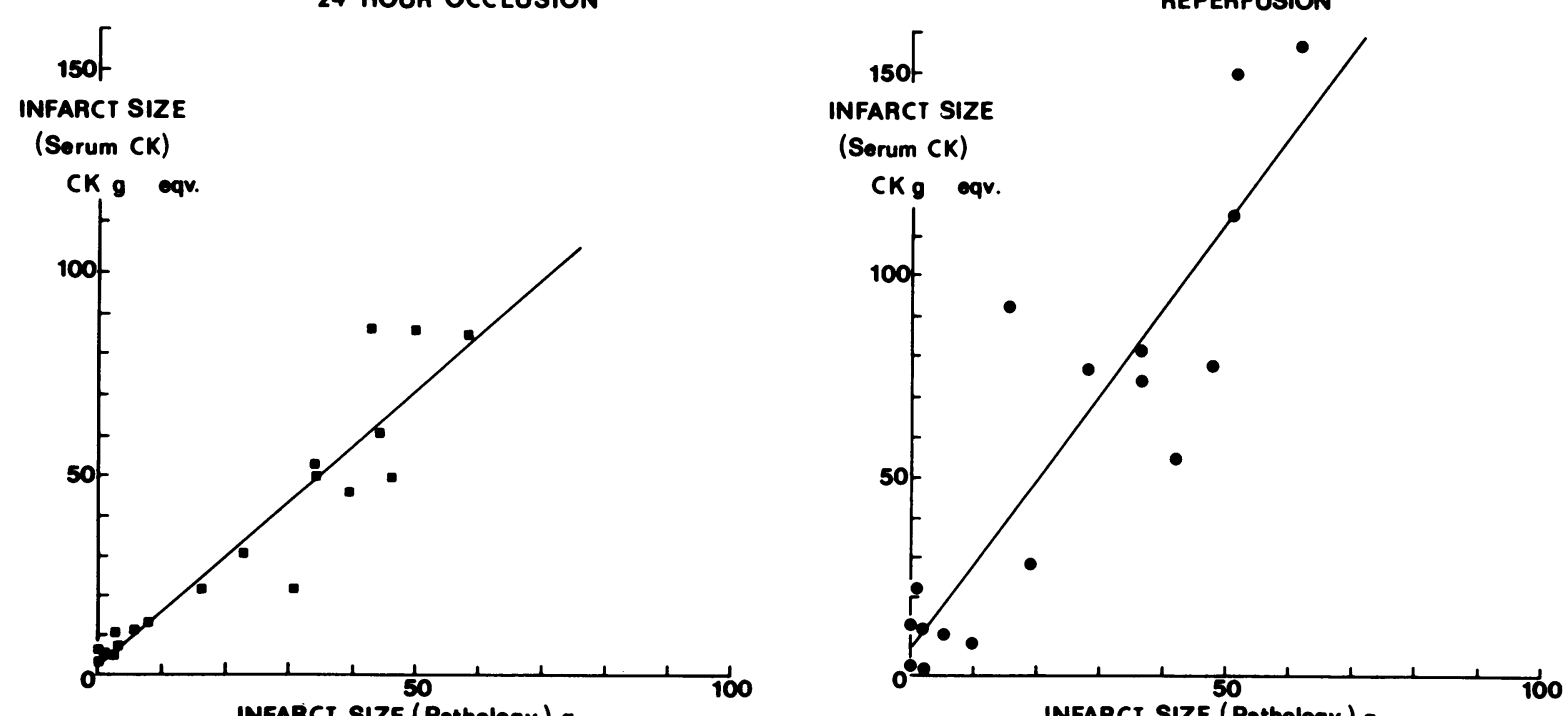

FIGURE 5 Infarct size calculated from appearance of CK in blood is plotted against infarct size measured by gross pathology for 19 dogs with 24-h occlusions and 17 dogs reperfused. The regression line was significantly steeper $(P<0.02)$ for the reperfused dogs. The standard error of the estimate was 10.45 for the 24 -h occlusion group and 23.37 for the reperfused group. 
0.87 and 0.94 , respectively. The relationships between these two techniques were also good for the reperfused group, having correlation coefficients of 0.94 and 0.90 , respectively.

It was observed in the present investigation that coronary artery reperfusion at 1 and $3 \mathrm{~h}$ after occlusion altered the time-course of appearance of CK in blood and configuration of the CK time-activity curve significantly. Peak blood CK occurred earliest when reperfusion was carried out at $1 \mathrm{~h}$ and latest when reperfusion did not occur. The rapid rise in blood CK immediately after reperfusion at either $1 \mathrm{~h}$ or $3 \mathrm{~h}$ suggested that CK was being washed out into the blood. Early appearance of CK after reperfusion was also noted by Jarmakani et al. (9). However, Jarmakani et al. (9), did not find that this observation altered the calculation of infarct size significantly. Using the formulas described by Shell et al. (7) to calculate infarct size from CK appearance in blood, the altered configuration of the CK curve after reperfusion would not necessarily lead to a different value for calculated infarct size unless the total amount of CK calculated or recovered in blood also changed. However, in contrast to the findings of Jarmakani et al. (9), and Bres- nahan et al. (8), this was observed in the present investigation. While the slope (or proportionality constant) between measured infarct size and that calculated from serial CK curves remained linear after reperfusion, it was significantly different from that observed with $24 \mathrm{~h}$ occlusion. This indicates that reperfusion led to an increased amount of CK appearing in the blood per gram of infarct or per unit of CK depleted from myocardium. This could be due to decreased time for local degradation of CK in myocardium subjected to reperfusion because of the increased rate of transport of $\mathrm{CK}$ into the systemic circulation.

In a previous study by Bresnahan et al. (8) two types of altered relationships between projected and calculated infarct size were noted among animals subjected to reperfusion, but the fraction of depleted myocardial $\mathrm{CK}$ released into the circulation was considered constant. For the group with excess CK release, infarction was apparently complicated by hemorrhage. For the other group, less CK release was observed than that projected before reperfusion; presumably indicative of protection of myocardium. If reperfusion had augmented CK recovered in blood in their study, as in the present investigation, their estimation of salvage

TABLE I

24-h Occlusion Group

\begin{tabular}{|c|c|c|c|c|c|c|c|c|}
\hline \multirow[b]{2}{*}{ Dog } & \multirow[b]{2}{*}{ Body wt } & \multirow[b]{2}{*}{$I_{p}$} & \multirow[b]{2}{*}{$\mathrm{IS}_{\mathrm{s}}$} & \multirow[b]{2}{*}{$\mathrm{IS}_{\mathrm{m}}$} & \multicolumn{2}{|c|}{ Total LV } & \multicolumn{2}{|r|}{ CK } \\
\hline & & & & & CK & Protein & RV & LV \\
\hline & $k g$ & $g$ & $C K$ g-eq & $C K g-e q$ & $I U / m l$ & $m g / m l$ & & IUlg wet wt \\
\hline \multicolumn{9}{|c|}{ Left circumflex occlusions } \\
\hline 1 & 31.0 & 0.0 & 5.48 & - & - & - & - & - \\
\hline 2 & 19.6 & 34.20 & 49.98 & - & - & - & - & - \\
\hline 3 & 22.3 & 2.30 & 5.25 & - & - & - & - & - \\
\hline 4 & 22.0 & 46.30 & 49.95 & - & - & - & - & - \\
\hline 5 & 28.6 & 7.46 & 12.57 & - & - & - & - & - \\
\hline 6 & 22.0 & 5.70 & 10.78 & - & - & - & - & - \\
\hline 7 & 24.0 & 2.70 & 10.63 & 0.99 & 59.4 & 1.66 & 1,665 & 1,485 \\
\hline 8 & 29.9 & 49.80 & 86.33 & 51.90 & 46.8 & 1.93 & 1,530 & 1,710 \\
\hline 9 & 25.0 & 44.10 & 60.88 & 21.80 & 59.4 & 1.60 & 1,688 & 1,498 \\
\hline 10 & 21.4 & 42.48 & 86.28 & 45.76 & 52.2 & 1.92 & 1,710 & 1,845 \\
\hline 11 & 22.3 & 39.40 & 46.13 & 24.21 & 46.5 & 1.64 & 1,388 & 1,388 \\
\hline 12 & 20.0 & 16.06 & 21.90 & 10.57 & 68.4 & 1.94 & 1,845 & 1,665 \\
\hline 13 & 19.1 & 33.92 & 53.19 & 35.88 & 50.4 & 1.72 & - & - \\
\hline 14 & 20.9 & 30.82 & 21.90 & 10.22 & 63.0 & 1.66 & 1,440 & 1,620 \\
\hline
\end{tabular}

Left anterior descending occlusions

\begin{tabular}{ccrrrrrrr}
15 & 31.0 & 1.00 & 5.90 & - & - & - & - & - \\
16 & 34.0 & 0.00 & 3.90 & - & - & - & - & - \\
17 & 62.5 & 2.64 & 6.57 & 0.53 & 60.0 & 1.52 & - & 1,910 \\
18 & 22.5 & 22.50 & 30.66 & 19.16 & 61.2 & 1.91 & 1,890 & 1,710 \\
19 & 27.2 & 58.50 & 84.19 & 76.26 & 45.0 & 1.92 & 1,575 & 1,620 \\
Mean & 26.6 & 23.15 & 34.34 & 27.03 & 55.7 & 1.77 & 1,637 & 1,627 \\
\pm SEM & \pm 2.24 & \pm 4.62 & \pm 6.77 & \pm 7.07 & \pm 2.35 & \pm 0.05 & \pm 56.8 & \pm 44.2 \\
\hline
\end{tabular}


TABLE II

Reperfusion Group

\begin{tabular}{|c|c|c|c|c|c|c|c|c|}
\hline \multirow[b]{2}{*}{ Dog } & \multirow[b]{2}{*}{ Body wt } & \multirow[b]{2}{*}{ IS $_{\mathrm{p}}$} & \multirow[b]{2}{*}{$\mathrm{IS}_{\mathrm{s}}$} & \multirow[b]{2}{*}{ IS $_{\mathrm{m}}$} & \multicolumn{2}{|c|}{ Total LV } & \multicolumn{2}{|r|}{ CK } \\
\hline & & & & & CK & Protein & RV & LV \\
\hline \multicolumn{9}{|c|}{ Left circumflex occlusions } \\
\hline 20 & 24.0 & 36.63 & 74.14 & - & - & - & - & - \\
\hline 21 & 31.0 & 9.80 & 8.30 & - & - & - & - & - \\
\hline 22 & 20.0 & 0.00 & 12.78 & 0.0 & 40.5 & 1.71 & 923 & 1,193 \\
\hline 23 & 22.3 & 0.87 & 21.72 & 2.45 & 66.6 & 1.61 & 1,575 & 1,665 \\
\hline 24 & 24.1 & 0.01 & 2.38 & 0.0 & 67.5 & 2.01 & 1,665 & 1,688 \\
\hline 25 & 23.0 & 1.98 & 1.96 & 0.91 & 59.4 & 1.58 & 1,305 & 1,485 \\
\hline 26 & 19.0 & 51.50 & 150.13 & 48.06 & 32.4 & 1.89 & 1,330 & 1,238 \\
\hline 27 & 25.0 & 41.89 & 54.80 & 31.29 & 46.8 & 1.82 & 1,373 & 1,440 \\
\hline 28 & 24.0 & 47.72 & 78.00 & 50.43 & 36.9 & 2.07 & 1,350 & 1,350 \\
\hline 29 & 27.0 & 18.93 & 28.11 & 1.54 & 55.8 & 1.66 & 1,530 & 1,485 \\
\hline 30 & 29.4 & 5.31 & 10.38 & 2.70 & 63.0 & 1.72 & 1,620 & 1,710 \\
\hline 31 & 22.0 & 61.60 & 156.88 & 55.16 & 45.9 & 1.67 & 1,485 & 1,485 \\
\hline 32 & 23.6 & 51.04 & 114.53 & 58.70 & 50.4 & 2.19 & 1,800 & 1,755 \\
\hline 33 & 24.0 & 36.36 & 81.74 & 15.66 & 56.7 & 1.92 & 1,530 & 1,575 \\
\hline 34 & 28.1 & 1.66 & 12.16 & 2.15 & 54.0 & 1.52 & 1,440 & 1,440 \\
\hline
\end{tabular}

Left anterior descending occlusions

\begin{tabular}{cllrccccc}
35 & 30.0 & 15.60 & 92.42 & - & - & - & - & - \\
36 & 25.4 & 27.99 & 77.05 & 15.50 & 68.4 & 1.84 & 1,890 & 1,868 \\
& & & & & & & & \\
Mean & 24.8 & 24.05 & 57.50 & 20.33 & 53.2 & 1.80 & 1,487 & 1,527 \\
+ SEM & \pm 0.81 & \pm 5.23 & \pm 12.36 & \pm 6.22 & \pm 3.08 & \pm 0.05 & \pm 63.4 & \pm 52.2 \\
\hline
\end{tabular}

in the group with decreased CK release would have been too conservative (8). However, since they examined dogs reperfused at $5 \mathrm{~h}$ as compared with reperfusion at 1 and $3 \mathrm{~h}$ in the present study, alterations of the ratio of CK recovered to CK lost from myocardium may have been less prominent.

The results of the present investigation are not only different from those of Bresnahan et al. (8), but also from those of Jarmakani et al. (9). In the latter study, overestimation of infarct size appeared more prominent, although not statistically, in the group with $24 \mathrm{~h}$ occlusion. In diametric opposition, our results indicate that overestimation of infarct size is more characteristic of the group with coronary artery reperfusion. Two differences in protocol between that of Jarmakani et al. (9), and the present study should be mentioned. First of all, the dogs in the study by Jarmakani et al. (9) were pretreated with morphine, a drug which constricts coronary vessels in conscious dogs (19). Secondly, the animals in the study by Jarmakani et al. (9) were treated with multiple doses of intravenous lidocaine. In contrast, no complicating drugs were administered to the conscious, unsedated dogs in the present study. Another point of difference from the results of Jarmakani et al. (9), was the consistent finding in the present study of gross hemorrhage in infarcts in the dogs with coronary artery reperfusion. A much greater percentage of infarcts after reperfusion (83\%) were hemorrhagic compared with that observed with 24-h occlusions (23\%). A high incidence of hemorrhagic infarction occurring after reperfusion was noted previously by Bresnahan et al. (8) in conscious dogs but has not been consistently observed in anesthetized dogs (20-22). In the study by Bresnahan et al., it was determined that the hemorrhagic myocardium did not influence the assay of CK in blood and this, by itself, would not explain the alterations observed in blood CK curves. An additional point of difference between the results in the present study and those of Bresnahan et al. (8) and Jarmakani et al. (9), is that the latter studies examined only left circumflex occlusions. In the present study, some left anterior descending artery occlusions were also examined. However, this difference cannot reconcile the discrepancies between the present and prior studies, since the major findings of the present investigation held true for the anterior descending as well as circumflex occlusions (Tables I, II).

A final point to consider is the variability in infarct size observed in conscious dogs either in the presence or absence of reperfusion. Even when the left circumflex artery was occluded for $24 \mathrm{~h}$, the resultant infarctions varied considerably in size. In contrast, a study 
by Jennings and Wartman indicated that occlusion of the left circumflex coronary artery produced a homogeneous myocardial infarction (10). One important difference between the present results and those of Jennings and Wartman is that the present study was conducted in the conscious animal, whereas the study by Jennings and Wartman (10) was conducted in anesthetized animals. Thus, the presence or absence of general anesthesia not only affects the incidence of gross hemorrhage in infarction after reperfusion (22), but may affect the size of infarction as well. This is an important consideration when using the left circumflex coronary occlusion model to study the effects of interventions that might protect the ischemic myocardium in the conscious dog.

The finding that reperfusion alters the relationship between calculated and measured infarct size is an important consideration when using the blood CK method to calculate infarct size both in experimental animals and in patients. In animals, this is important since most studies are conducted without continuous measurement of the effectiveness of the occluding device, as was done in this study with a flowmeter. The partial release of the occlusion that happens frequently using different balloon cuffs or snares may be responsible for inaccurate conclusions. Moreover, patients with myocardial infarction may have: $(a)$ subtotal coronary occlusions, (b) alternating coronary spasm and relaxation, or $(c)$ a dynamic process with clot formation and lysis. Under all these conditions reperfusion occurs, which would result in an altered relationship between calculated and measured infarct size. Most importantly, however, in patients who undergo aorta-coronary bypass surgery, the application of the formula as used in nonoperated patients may also result in overestimation of infarct size and thus erroneously suggest that the operation extended the infarction. Finally, it is conceivable that any intervention that increases perfusion of ischemic myocardium may increase washout of CK into the blood.

In summary, the major findings of the present investigation are: $(a)$ reperfusion alters the shape of the serial blood CK curve and results in a different linear relationship between calculated and measured infarct size, resulting in greater recovery of CK in blood per unit of infarcted myocardium; (b) infarct size measured by gross pathology and confirmed histologically correlates extremely well with infarct size calculated with the technique of Kjekshus and Sobel (6), e.g. by myocardial CK depletion, and (c) left circumflex occlusion in the conscious dog results in a range of infarct sizes ranging from at least 0 to $51.5 \mathrm{~g}$.

\section{APPENDIX I}

Calculation of infarct size $\left(I S_{m}\right)$ from measurement of myocardial CK depletion.

$$
\mathrm{IS}_{\mathrm{m}}(\text { gram })=\frac{\left(\mathrm{CK}_{\mathrm{N}}-\mathrm{CK}_{\mathrm{T}}\right) \mathrm{wt} \mathrm{L}_{\mathrm{LV}}}{0.75 \mathrm{CK}_{\mathrm{N}}},
$$

where: $\mathrm{CK}_{\mathrm{N}}=\mathrm{CK}$ concentration, (International Units per gram) in the normal left ventricle; $\mathrm{CK}_{\mathrm{T}}=\mathrm{CK}$ concentration (International Units per gram) in the homogenized total left ventricle; $w t_{L V}=$ weight of left ventricle (gram); and $\left(\mathrm{CK}_{\mathrm{N}}\right.$ $\left.-\mathrm{CK}_{\mathrm{T}}\right) \times \mathrm{wt}_{\mathrm{LV}}=$ total amount of $\mathrm{CK}$ depleted from the myocardium.

\section{APPENDIX II}

Calculation of infarct size $\left(I S_{s}\right)$ based on an analysis of serial plasma CK levels.

$$
\mathrm{IS}_{\mathrm{s}}=\frac{\tilde{\mathrm{DV}}}{\mathrm{P}_{\mathrm{CK}}\left(\mathrm{CK}_{\mathrm{N}}-\mathrm{CK}_{\mathrm{I}}\right)} \cdot \mathrm{BW} \cdot \int_{0}^{\mathrm{t}} \mathrm{f}(\mathrm{t}) \cdot d \mathrm{t},
$$

with $\tilde{\mathrm{DV}}=$ distribution space/unit body $\mathrm{wt}=0.114$ and $\mathrm{P}_{\mathrm{CK}}$ $=$ proportion of $\mathrm{CK}$ released $/ \mathrm{CK}$ depleted $=0.3 ; \mathrm{BW}=$ body weight (kilogram); $\mathrm{CK}_{\mathrm{N}}, \mathrm{CK}_{\mathrm{I}}=\mathrm{CK}$ activity (International Unit per gram myocardium) of normal and infarcted myocardium $\left(\mathrm{CK}_{\mathrm{N}}-\mathrm{CK}_{\mathrm{I}}\right)=800$. The calculation is based on the following mathematical model:

$$
f(t)=\frac{d E}{d t}-K_{d} E
$$

where $f(t)$ is the CK appearance function (International Unit per milligram per minute); $\mathrm{E}=$ plasma $\mathrm{CK}$ activity (International Units per milliliter) at any instant; and $\mathrm{K}_{\mathrm{d}}=$ fractional disappearance rate of $\mathrm{CK}$ per minute $=-0.0045$.

\section{ACKNOWLEDGMENTS}

The technical assistance of P. Quinn and S. Hale and the help in preparation of the manuscript by $\mathrm{E}$. Tenenholtz and C. Conran are appreciated.

This work was supported in part by U. S. Public Health Service grants HL17459, HL17665, and Contract I-HV-53000.

\section{REFERENCES}

1. Nydick, I., F. Wroblewski, and J. S. Ladue. 1955. Evidence for increased serum glutamic oxaloacetic transaminase (SGOT) activity following graded myocardial infarcts in dogs. Circulation. 12: 161-168.

2. Agress, C. M., H. I. Jacobs, S. F. Glassner, M. A. Lederer, W. G. Clark, F. Wroblewski, A. Karmen, and J. S. Ladue. 1955. Serum transaminase levels in experimental myocardial infarction. Circulation. 11: 711-713.

3. Lemley-Stone, J., J. M. Merrill, J. T. Grace, and G. R. Meneeley. 1955. Transaminase in experimental myocardial infarction. Am. J. Physiol. 183: 555-558.

4. Jennings, R. B., J. P. Kaltenbach, and G. W. Smetters. 1957. Enzymatic changes in acute myocardial ischemic injury. Glutamic oxaloacetic transaminase, lactic dehydrogenase, and succinic dehydrogenase. Arch. Pathol. 64: $10-16$.

5. Chapman, B. L. 1971. Correlation of mortality rate and serum enzymes in myocardial infarction. Br. Heart J. 33: $643-646$.

6. Kjekshus, J. K., and B. E. Sobel. 1970. Depressed myocardial creatine phosphokinase activity following experimental myocardial infarction in rabbit. Circ. Res. 27: 403-414.

7. Shell, W. E., J. K. Kjekshus, and B. E. Sobel. 1971. Quantitative assessment of the extent of myocardial infarction 
in the conscious dog by means of analysis of serial changes in serum creatine phosphokinase activity J. Clin. Invest. 50: 2614-2625.

8. Bresnahan, G. F., R. Roberts, W. E. Shell, J. Ross, and B. E. Sobel. 1974. Deleterious effects due to hemorrhage after myocardial reperfusion. Am. J. Cardiol. 33: 82-86.

9. Jarmakani, J. M., L. Limbird, R. C. Graham, and R. A. Marks. 1976. Effect of reperfusion on myocardial infarct, and the accuracy of estimating infarct size from serum creatine phosphokinase in the dog. Cardiovasc. Res. 10: 245-253.

10. Jennings, R. B., and W. B. Wartman. 1957. Production of an area of homogeneous myocardial infarction in the dog. Arch. Pathol. 63: 580-585.

11. Heyndrickx, G. R., R. W. Millard, R. J. McRitchie, P. R Maroko, and S. F. Vatner. 1975. Regional myocardial functional and electrophysiological alterations following brief coronary artery occlusion in conscious dogs. J. Clin. Invest. 56: 978-985.

12. Vatner, S. F., D. Franklin, and R. L. Van Citters. 1970. Simultaneous comparison and calibration of the Doppler and electromagnetic flowmeters. J. Appl. Physiol. 29: 907-910.

13. Gornall, A. G., C. J. Bardawill, and M. M. David. 1949. Determination of serum protein by means of the biuret reaction. J. Biol. Chem. 177: 751-766.

14. Rosalki, S. B. 1967. An improved procedure for serum creatine phosphokinase determination. J. Lab. Clin. Med. 69: 696-705.

15. Armitage, P. 1973. In Statistical Methods in Medical Research. Blackwell Scientific Publications Ltd., Oxford.
16. Bleifeld, W., D. Mathey, P. Hanrath, H. Buss, and S. Effert. 1977. Infarct size estimated from serial creatine phosphokinase in relation to left ventricular hemodynamics. Circulation. 55: 303-311.

17. Norris, R. M., R. M. L. Whitlock, C. Barratt-Boyes, and C. W. Small. 1975. Clinical measurement of myocardial infarct size. Modification of a method for the estimation of total creatine phosphokinase release after myocardial infarction. Circulation. 51: 614-620.

18. Roe, C. R., F. R. Cobb, and C. F. Starmer. 1977. The relationship between enzymatic and histologic estimates of the extent of myocardial infarction in conscious dogs with permanent coronary occlusion. Circulation. 55 (3): 438-448.

19. Vatner, S. F., J. D. Marsh, and J. A. Swain. 1975. Effects of morphine on coronary and left ventricular dynamics in conscious dogs. J. Clin. Invest. 55: 207-217.

20. Ginks, W. R., H. D. Sybers, P. R. Maroko, J. W. Covell, B. E. Sobel, and J. Ross. 1972. Coronary artery reperfusion. II. Reduction of myocardial infarct size at one week after the coronary occlusion. J. Clin. Invest. 51: 2717-2723.

21. Maroko, P. R., P. Libby, W. R. Ginks, C. M. Bloor, W. E. Shell, B. E. Sobel, and J. Ross. 1972. Coronary artery reperfusion. I. Early effects on local myocardial function and the extent of myocardial necrosis. J. Clin. Invest. 51: $2710-2716$

22. Diaz, P. E., S. F. Vatner, and P. R. Maroko. 1976. Factors determining the appearance of hemorrhage following coronary artery reperfusion. Circulation. 54 (Suppl. II): 69. 